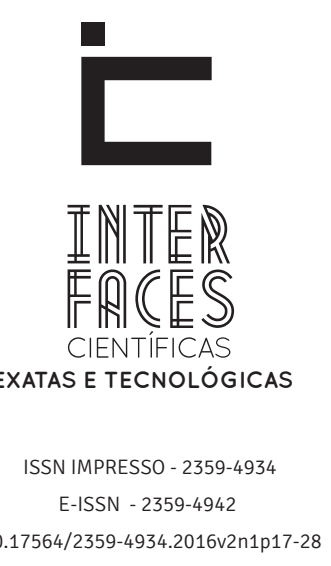

\title{
ACORDO DE COMPENSAÇÃO COFFSED EM ITENS DE DEFESA: UMA PERSPECTIVA DO SETOR AERONÁUTICO
}

Robson Alves Silva ${ }^{1}$

\section{RESUMO}

Esta pesquisa teve como meta avaliar criticamente em que medida os Acordos de Offset contribuem para o desenvolvimento da indústria de defesa na perspectiva do setor aeronáutico brasileiro. Partiu-se da análise do mercado Norte-americano no Pós-Segunda Guerra onde foram desenhadas as primeiras experiências em compensações militares, beneficiando países da Europa e o Japão. Em seguida, iniciou-se uma análise das experiências no setor aeronáutico de defesa no Brasil, com foco nos contratos de importação da Força Aérea e no papel do poder de compra do Estado brasileiro.

\section{PALAVRAS-CHAVE}

Offset, desenvolvimento, setor aeronáutico e indústria de defesa. 


\section{ABSTRACT}

This research was aimed to evaluate critically what extent the Offset Agreements contribute to the development of the defense industry in the perspective of the Brazilian aviation industry. It started from the North American market analysis in the post World War Two the first experiments in military compensation where they were drawn, benefiting countries in Europe and Japan. Then began a review of experiences in the aviation sector of defense in Brazil, focused on import contracts of the Air Force and the role of the state purchasing power.

\section{KEYWORDS}

Offset, development, aviation industry and defense industry.

\section{RESUMEN}

Esta investigación tuvo como objetivo analizar críticamente en qué medida los acuerdos Offset contribuyen al desarrollo de la industria de defensa, en la perspectiva de la industria de aviación brasileña. Todo comenzó a partir del análisis del mercado de América del Norte en el posguerra de la Segunda Guerra Mundial, donde se diseñaron los primeros experimentos en compensación militar beneficiando países de Europa y Japón. En seguida, se comenzó un análisis de las ex- periencias en el sector de aeronáutica militar del Brasil, centrándose en los contratos de importación de la Fuerza Aérea y el papel del poder adquisitivo del país.

\section{PALABRAS CLAVE}

Offset, desarrollo, la industria de la aviación y la industria de defensa. 


\section{INTRODUÇ̄̃̃O}

Offsets e outras formas de countertrade ${ }^{2}$ são práticas de comércio comumente utilizadas no comércio exterior. Essas práticas não estão restritas ao comércio internacional de armamento, sequer envolvem apenas compras governamentais. $\mathrm{Na}$ realidade são práticas que envolvem todo tipo de bens e serviços negociados e representam até $30 \%$ do comércio internacional (BAUNER; DUNNE, 2004).

0 presente trabalho buscou responder a seguinte questão: em que medida os Acordos de Offset contribuem para o desenvolvimento do setor aeronáutico na indústria de defesa brasileira?

O objetivo central deste artigo, portanto, é contribuir para a compreensão da problemática envolvida nesse questionamento e demonstrar a importância dos Acordos de Offset no processo de desenvolvimento e transferência de tecnologia em itens aeronáuticos de defesa, bem como a criação de mecanismos de incentivo e ampliação à indústria nacional. A construção do argumento leva em consideração o nível de maturidade tecnológica da indústria de defesa e sua capacidade em absorver novos conhecimentos.

0 trabalho foi concebido com os seguintes objetivos específicos: 1 . Sintetizar e analisar criticamente a experiência dos EUA em Acordos de Offset, permitindo dimensionar essas experiências e os ganhos reais que obtiveram. Buscou-se também avaliar os resultados alcançados nos Acordos de Offset desenvolvidos no Brasil, especificamente os que estão sob a responsabilidade da Força Aérea; 2. Refletir criticamente acerca da indústria de defesa nacional, com vistas a avaliar a capacidade de absorção de novas

2. Countertrade também pode ser considerado como uma das muitas formas de compensação em defesa, para compensar um país comprador. A principal diferença entre um genérico offset e countertrade, ambas as práticas comuns no comércio internacional de defesa, é o envolvimento de dinheiro. No countertrade, os bens são pagos por meio de permutas ou outros mecanismos, sem a troca de dinheiro, enquanto em outros deslocamentos de defesa, dinheiro é a medida e o meio de troca. tecnologias viabilizadas pelos instrumentos de compensação no setor aeronáutico; e 3. Propor um debate qualificado acerca das vantagens dos Acordos de Offset, apresentando o cenário no qual o offset tem se desenvolvido no Brasil.

Com o propósito de cumprir o objetivo mais amplo deste trabalho que é demonstrar a importância dos Acordos de Offset no processo de desenvolvimento da indústria de defesa do Brasil, especificamente no setor aeronáutico, passa-se a seguir à definição de Offset de modo a proporcionar uma visão mais objetiva do processo de compensação comercial, industrial e tecnológico em itens de defesa.

\subsection{CONCEITO DE OFFSET}

Antes de avaliarmos as tendências e as complexidades dos impactos dos Acordos de Offset sobre aquisições em itens de defesa, passaremos ao conceito de Offset e a sua abrangência, a fim de permitir um direcionamento mais adequado à proposta de pesquisa aqui apresentada.

O Escritório de Indústrias Estratégicas e de Segurança Econômica do Departamento de Comércio dos EUA (BIS), que tem dentre suas competências a emissão de relatórios anuais ao Congresso Norte-americano acerca dos impactos de acordos de compensação em comércio de defesa nos EUA, define Offset como sendo acordos de compensação industriais exigidos por governos estrangeiros como condição de compra de artigos e serviços de defesa (UNITED..., 2007).

O Brasil adota semelhante definição de Offset, como prevê a Portaria $n^{\circ} 764 / \mathrm{MD} / 2002^{3}$, qual seja, é a política de compensação comercial, industrial e tecnológica do Ministério da Defesa, cujos objetivos

3. Portaria Normativa $n^{\circ} 764 / M D$, de 27 de dezembro de 2002 , que aprova a política e as diretrizes de Compensação Comercial, Industrial e Tecnológica do Ministério da Defesa. 
versam sobre a promoção do crescimento dos níveis tecnológicos e qualitativos das indústrias de defesa, bem como o fomento e o fortalecimento dos setores de interesse do Ministério da Defesa.

Os Acordos de Compensação no Brasil assumem as duas formas previstas pelo BIS - direta e indireta -, conforme disposto na ICA n 360-1/20054:

É o instrumento legal que formaliza o compromisso e as obrigações do fornecedor estrangeiro para compensar as importações realizadas nos seguintes casos:

a) diretamente, pelas Forças Armadas; e

b) indiretamente, pelas Forças Armadas, nas contratações de empresas nacionais que tenham que realizar importações vinculadas ao cumprimento dos contratos.

A demanda por esses acordos teve origem nos anos seguintes à Segunda Guerra Mundial em grande medida por meio da produção e coprodução de arranjos militares entre os EUA e aliados, principalmente, países da Europa e Japão (NACKMAN, 2011). O objetivo inicial desses acordos era o de incentivar a aquisição de sistemas e armas interoperáveis da indústria americana pelos países aliados.

Nessa época, o EUA iniciava esforços em prol da reconstrução dos países aliados devastados pela guerra, por meio de remessa de recursos, cujo objetivo principal era a criação de um mercado capaz de acolher produtos semi-industrializados e industrializados, sendo que destes $70 \%$ eram de origem norte -americana (DW, [s.d.]).

Podemos concluir que conceituar Offset não é uma tarefa fácil, especialmente, porque essas compensações geralmente envolvem processos de terceirização estratégica, transferência de tecnologia e aquisição de componentes que muitas vezes estão fora do escopo do projeto pretendido inicialmente. (MOWERY, 1999)

Passaremos à análise da legislação que norteia as operações de compensação no Brasil, com vistas a de-

4. Instrução Normativa do Comando da Aeronáutica n 360-1/2005, aprovada pela Portaria n 1.397/GC-4, de 13 de dezembro de 2005. finir o seu marco regulatório e determinar os limites de atuação tanto do governo quanto da indústria.

\subsection{MARCO REGULATÓRIO}

O Estado brasileiro dedicou um capítulo exclusivo na Constituição Federal de 1988, para tratar do tema Ciência e Tecnologia. Os temas tecnologia e inovação devem receber tratamento prioritário por parte do Estado, conforme prevê o art. 218 da CF/88, com vistas à solução de problemas estruturais brasileiros e o desenvolvimento do sistema produtivo nacional. A CF/88 prevê também o apoio à formação de recursos humanos nas áreas de ciência e tecnologia, bem como a criação de condições favoráveis às empresas brasileiras que invistam em desenvolvimento tecnológico.

A Lei $n^{\circ} 8.666 / 93^{5}$, que regulamenta 0 art. 37, inciso XXI, da Constituição Federal de 1988, instituiu normas específicas sobre licitações e contratos para a Administração Pública, no seu art. $3^{\circ}, \S 11$, onde estabelece regras para que os próprios editais de licitação já prevejam, para contratação de bens, serviços e obras, a exigência de medidas de compensação comercial, industrial e tecnológica nas contratações promovidas por órgãos ou entidades integrantes da Administração Pública.

O Ministério da Defesa, por meio da Portaria Normativa n 764/MD, de 27 de dezembro de 2002, aprovou a política e as diretrizes de compensação comercial, industrial e tecnológica para o ministério, com vistas a regulamentar os Acordos de Offset no âmbito das Forças Armadas.

A referida norma estabeleceu, ainda, que contratos de importação assumidos pelas Forças Armadas, com valor líquido FOB acima de US\$ 5.000.000,00, ou valor equivalente em outra moeda, tenham obrigatoriamente atrelado ao contrato principal um Acordo de Compensação.

5. Lei ${ }^{\circ} 8.666$, de 21 de junho de 1993, Regulamenta 0 art. 37, inciso XXI, da Constituição Federal, institui normas para licitações e contratos da Administração Pública e dá outras providências. 
No âmbito do Comando da Aeronáutica, foi editada a Portaria no 1.396/GC-4, de 13 de dezembro de 2005, onde prevê a instituição de um Comitê de Compensação Comercial, que tem por atribuição a condução e a direção das ações necessárias à aplicação da Política e Estratégia de Compensação, Industrial e Tecnológica no âmbito da Aeronáutica.

Já a Instrução Normativa n 360-1, aprovada pela Portaria $n^{0} 1.397 / G C 4$, de 13 de dezembro de 2005, estabelece preceitos claros e objetivos que permitem, a todos os órgãos da Aeronáutica, a condução adequada das atividades relacionadas à compensação.

Aprovado pelo Decreto $n^{\circ} 6.703$, de 18 de dezembro de 2008, a Estratégia Nacional de Defesa (END) foi concebida e associada, também, à ideia de estratégia nacional de desenvolvimento, criando condições ao Estado brasileiro de construir seu próprio modelo, utilizando-se das tecnologias e dos conhecimentos de defesa como uma ferramenta de fomento ao desenvolvimento nacional. Dentre as diretrizes estabelecidas pela Estratégia Nacional de Defesa, destaca-se a capacitação da Base Industrial de Defesa (BID) em prol da autonomia em tecnologias indispensáveis à defesa. Especificamente, no capítulo em que a END trata da estruturação das Forças Armadas, em relação aos seus equipamentos de defesa, o planejamento deverá priorizar a compensação comercial, industrial e tecnológica (BRASIL, [s.d]).

Para compreender as características assumidas pela legislação brasileira que trata dos Acordos de Compensação Comercial, passa-se a descrever a seguir os caminhos trilhados tanto pelos EUA quanto pelo Brasil, levando-se em consideração as especificidades de cada país.

\section{OFFSETEM ITENS DE DEFESA}

Descrever as experiências comerciais, envolvendo Acordos de Offset patrocinados pelos EUA, permite um entendimento mais apurado sobre as características comerciais e as limitações impostas pelo governo norte-americano acerca do processo de exportação e transferência de tecnologia em itens de defesa a terceiros países.

O Bureau of Industry and Security (BIS), instituição da estrutura do governo norte-americano, parte integrante do Departamento de Comércio, tem por competência o controle das exportações de bens e tecnologias sensíveis. Outra atribuição dada ao BIS é a de efetuar a gestão do sistema de tratados que regulam o comércio de bens que envolvem alta tecnologia, garantindo a proteção da indústria dos EUA quanto à produção e comercialização de bens de uso dual.

O conhecimento mais apurado dessas experiências comerciais permitirá, também, ao governo brasileiro melhor lidar com as determinações e limitações comerciais impostas pelo International Traffic in Arms Regulations $\left(\right.$ ITAR $^{5}$, conjunto de normas que regula e controle de forma unilateral do comércio de itens de defesa que estejam catalogados no United States Munitions List (USML) ${ }^{7}$, parte integrante da Arms Exports Control Act, $(A E C A)^{8}$, criados inicialmente para controlar as armas que tivessem como destino o Bloco do Pacto de Varsóvia, mas que é utilizado, atualmente, como um cerceador de transferência tecnológica, sob a justificativa de se tratar de um mecanismo que visa preservar a segurança nacional dos EUA.

\subsection{EXPERIÊNCIA NORTE-AMERICANA}

A origem dos Acordos de Offset militares se deu em função da política norte-americana em promover a compra de sistemas de armas e fomentar a economia dos países aliados nas décadas de 1950 e 1960,

6. Trata-se de um Regulamento sobre o Tráfico Internacional de Armas do governo dos EUA que tem por propósito controlar a exportação e importação de bens sensíveis relacionados à defesa, com vistas a salvaguardar a segurança dos EUA.

7. Trata-se de uma lista dos bens, serviços e tecnologia em itens de defesa controlados pelo ITAR, que só podem ser compartilhados mediante autorização do governo norte-americano.

8. Trata-se da Lei de Controle de Exportação de Armas do governo dos EUA. 
por meio do licenciamento de produção e coprodução de bens destinados, principalmente, à Europa e ao Japão (EIGHTEENTH..., 2013).

A necessidade de partilhar riscos e buscar apoio financeiro, bem como as crescentes capacidades tecnológicas fizeram com que a demanda por compensações aumentasse cada vez mais no campo militar (SALZMANN, 2004).

Nos EUA, 32 empresas firmaram 173 novos acordos de compensação com governos estrangeiros totalizando US\$ 15 bilhões, entre os anos de 1993 e 1996. Esses acordos foram suportados por contratos de defesa na ordem de US\$ 29 bilhões, onde apenas cinco empresas foram responsáveis por $78 \%$ do total desses novos acordos de compensação e $80 \%$ dos valores dos contratos de exportação; no mesmo período, $38 \%$ do montante dos acordos fechados se referiam a compensações diretas e $58 \%$ de compensações indiretas, sendo que $4 \%$ foram consideradas não especificadas 9 .

Num período mais abrangente de análise (19932012), verificou-se o desempenho das exportações de 54 empresas norte-americanas com acordos de compensação vinculados, onde foram firmados 888 contratos de venda com 45 países, totalizando US\$ 149 bilhões. Os acordos de compensação foram avaliados na ordem de US\$94,8 bilhões, conforme a Tabela 1.

Tabela 1 - Resumo dos contratos de exportação em defesa firmados com Acordos de Offset

\begin{tabular}{ccccccc}
\hline Ano & $\begin{array}{c}\text { Valor do } \\
\text { Contrato } \\
\text { (U\$ milhões) }\end{array}$ & $\begin{array}{c}\text { Valor do Acor- } \\
\text { do de Offset } \\
\text { (Û\$ milhões) }\end{array}$ & $\begin{array}{c}\text { Percentual } \\
\text { do Offset no } \\
\text { Contrato }\end{array}$ & $\begin{array}{c}\text { Empresas EUA } \\
\text { (quantidade) }\end{array}$ & $\begin{array}{c}\text { Acordos } \\
\text { (quantidade) }\end{array}$ & $\begin{array}{c}\text { Países/Acordos } \\
\text { Multilaterais } \\
\text { (quantidade) }\end{array}$ \\
\hline 1993 & 13,935 & 4,784 & $34,33 \%$ & 17 & 28 & 16 \\
1994 & 4,792 & 2,049 & $42,75 \%$ & 18 & 49 & 20 \\
1995 & 7,632 & 6,204 & $81,30 \%$ & 21 & 48 & 18 \\
1996 & 3,120 & 2,432 & $77,94 \%$ & 16 & 53 & 19 \\
1997 & 5,925 & 3,826 & $64,56 \%$ & 15 & 60 & 20 \\
1998 & 3,079 & 1,786 & $57,99 \%$ & 14 & 42 & 17 \\
1999 & 5,657 & 3,457 & $61,11 \%$ & 11 & 45 & 11 \\
2000 & 6,576 & 5,705 & $86,75 \%$ & 10 & 43 & 16 \\
2001 & 7,116 & 5,550 & $77,99 \%$ & 12 & 35 & 13 \\
2002 & 7,406 & 6,095 & $82,29 \%$ & 12 & 41 & 17 \\
2003 & 7,293 & 9,110 & $124,92 \%$ & 11 & 32 & 13 \\
2004 & 4,928 & 4,330 & $87,87 \%$ & 14 & 40 & 18 \\
2005 & 2,260 & 1,464 & $64,79 \%$ & 08 & 25 & 18 \\
2006 & 5,265 & 3,655 & $69,42 \%$ & 15 & 48 & 21
\end{tabular}

9. Third annual report on offsets in defense trade prepared by the Department of Commerce's Bureau of Export Administration (BXA), as required by the 1992 amendments to Section 309 of the Defense Production Act

of 1950, as amended. The report includes 1996 offsets data reported by U.S. firms in the last year and combines it with data collected previously from 1993-1995. 


\begin{tabular}{|c|c|c|c|c|c|c|}
\hline 2007 & 6,736 & 5,438 & $80,73 \%$ & 11 & 44 & 19 \\
\hline 2008 & 6,294 & 3,672 & $58,35 \%$ & 16 & 54 & 17 \\
\hline 2009 & 10,841 & 6,731 & $62,08 \%$ & 15 & 61 & 21 \\
\hline 2010 & 4,239 & 2,783 & $65,65 \%$ & 16 & 35 & 14 \\
\hline 2011 & 10,879 & 5,586 & $51,35 \%$ & 09 & 62 & 27 \\
\hline 2012 & 25,025 & 10,108 & $40,39 \%$ & 11 & 43 & 17 \\
\hline $\begin{array}{l}\text { Total ou } \\
\text { Média }\end{array}$ & 148,989 & 94,763 & $63,60 \%$ & 54 & 888 & 47 \\
\hline
\end{tabular}

Nota: Devido ao arredondamento, os totais podem não corresponder exatamente. Determinados dados de anos anteriores foram revistos. Os valores mostrados não foram corrigidos pela inflação.

Fonte: Banco de Dados BIS offset, com adaptação.

Quando comparados em termos percentuais, os valores das exportações em defesa relacionados com compensação e os valores totais das exportações de mercadorias norte-americanas parecem ínfimos, po- rém quando analisados em termos de valor, percebese a grandeza da Base Industrial de Defesa dos EUA, conforme revela a Tabela 2, abaixo:

Tabela 2 - Exportações de mercadorias dos EUA e Atividades de Offset divulgadas

\begin{tabular}{ccccccc}
\hline Ano & $\begin{array}{c}\text { Total de } \\
\text { Mercadorias } \\
\text { Exportadas } \\
\text { (U\$ milhões) }\end{array}$ & $\begin{array}{c}\text { Exportações de } \\
\text { Mercadorias } \\
\text { Classificadas } \\
\text { como Defesa } \\
\text { (Û\$ milhões) }\end{array}$ & $\begin{array}{c}\text { Percentual de } \\
\text { Exportações de } \\
\text { Mercadorias } \\
\text { Classificadas como } \\
\text { Defesa em relação ao } \\
\text { total das Exportações }\end{array}$ & $\begin{array}{c}\text { Valor das Vendas } \\
\text { Classificadas } \\
\text { como Defesa em } \\
\text { Contratos com } \\
\text { Acordos de Offset } \\
\text { (U\$ milhões) }\end{array}$ & $\begin{array}{c}\text { Valor dos } \\
\text { Acordos de } \\
\text { Compensação } \\
\text { Relatados } \\
\text { (U\$ milhões) }\end{array}$ & $\begin{array}{c}\text { Valor das } \\
\text { de Offónset } \\
\text { Relatadas } \\
\text { (U\$ milhões) }\end{array}$ \\
\hline 2003 & 724,771 & 11,509 & $1,59 \%$ & 7,293 & 9,110 & 3,566 \\
2004 & 814,875 & 11,884 & $1,46 \%$ & 4,928 & 4,330 & 4,935 \\
2005 & 901,082 & 12,835 & $1,42 \%$ & 2,260 & 1,464 & 4,722 \\
2006 & $1,025,968$ & 16,629 & $1,62 \%$ & 5,265 & 3,655 & 4,706 \\
2007 & $1,148,199$ & 16,894 & $1,47 \%$ & 6,736 & 5,438 & 3,805 \\
2008 & $1,287,442$ & 16,594 & $1,29 \%$ & 6,294 & 3,672 & 3,291 \\
2009 & $1,056,043$ & 14,796 & $1,40 \%$ & 10,841 & 6,731 & 3,495 \\
2010 & $1,278,495$ & 15,304 & $1,20 \%$ & 4,239 & 2,783 & 3,608 \\
2011 & $1,480,290$ & 14,852 & $1,00 \%$ & 10,879 & 5,586 & 3,880 \\
\hline 2012 & $1,545,709$ & 17,220 & $1,11 \%$ & 25,025 & 10,108 & 3,438 \\
\hline
\end{tabular}

* 2010 e 2011 os dados foram revisados pelo Censo. Os valores apresentados não foram ajustados pela inflação.

Fontes: Banco de Dados BIS Offset e os EUA Census Bureau, os dados de utilização final de exportação e de Comércio de mercadorias dos EUA - Balanço de Pagamentos Base vs. Base do Censo, com adaptação. 
Apesar de o governo dos EUA exercer uma forte fiscalização em atividades de acordo de compensação e considerá-las economicamente ineficientes e prejudiciais ao comércio, para os empresários do ramo de defesa a visão é diferente. Eles enxergam as compensações como uma realidade do mercado para as empresas que tratam com vendas internacionais. Há de fato um ganho em rede global com oportunidades de negócio para os EUA na fabricação de itens de defesa atrelados a contratos de exportação com compensação é o que se percebe quanto analisado o período 2010-2012, onde houve uma entrada adicional de US\$ 64 bilhões para a Base Industrial de Defesa e a criação de 240 mil novas oportunidades de empregos (EIGHTEENTH..., 2013).

Verifica-se dos números apresentados que os Acordos de Offset são uma realidade da prática comercial global e que os processos de transferência tecnológica em muitos casos são promovidos por esses acordos de compensação. Passa-se, portanto, à análise das políticas de Offset desenvolvidas no Brasil, com vistas a elaborar uma análise crítica acerca das vantagens desses acordos, também para a indústria de defesa brasileira, permitindo identificar pontos de convergência com os modelos de negócios praticados por empresas norte-americanas e que efetivamente possam ser empregadas no contexto brasileiro.

\subsection{EXPERIÊNCIA BRASILEIRA}

A indústria de defesa no Brasil passou por bons e maus momentos. Ainda no final do século passado, - Brasil possuía uma promissora indústria bélica. 0 início dos anos 1970 foi marcado pelo chamado "Milagre Econômico", período compreendido entre 1968 e 1973, caracterizado por um excepcional crescimento econômico e pelo aumento extraordinário do PIB, que saltou de $9,8 \%$ para $19,46 \%$, à época. Porém, esse período também ficou marcado pelo aumento da inflação e uma consequente concentração de renda (SINGER, 1972).
A partir de 1973, a economia brasileira começou a encolher e se agravou com o chamado "Choque do Petróleo em 1974" (MARQUES, 1989), quando o preço do barril subiu de US\$3,37 para US\$11,25. Essa crise pressionou a inflação em todo o mundo e o Brasil foi pego em cheio, saindo de um patamar inflacionário de $15,5 \%$ para $34,5 \%$, já em 1974 . A balança comercial brasileira sofreu diretamente os impactos da crise do petróleo em função do volume de recursos despendidos para custear a importação do óleo (MARQUES, 1989).

A partir dos anos 1980, o país experimentou baixos índices de crescimento econômico, coincidindo com a alta da inflação e a instabilidade macroeconômica que perdurou até meados da década de 1990 (MORCEIRO, 2012).

O Brasil aparece, atualmente, entre os 15 países que mais gastaram no seguimento militar. Em relação a 2013, o Brasil ocupou o $11^{\circ}$ lugar no ranking, passando a Itália que enfrenta dificuldades econômicas em função da crise iniciada em 2008, e viu os gastos com despesas militares caírem na ordem de $25 \%$ desde o início da crise, e 8,8\% só em 2014.

A economia desacelerou e o governo enfrenta grandes protestos sociais desde a reeleição do atual governo. 0 crescimento do PIB em 2014 foi projetado para apenas 0,3\%, no entanto, os gastos do Brasil ainda foram $41 \%$ maiores do que em 2005 , e continuou com uma tendência de crescimento bastante consistente. Esta tendência geral de aumento é reflexo do Programa de Reaparelhamento das Forças Armadas em curso no Brasil, que culminou em 2014, com a assinatura de um contrato comercial para compra de 36 aeronaves de combate (Gripen NG) da Suécia estimado em US $\$ 5,8$ bilhões.

As empresas nacionais beneficiárias desses acordos têm papel importante nesse processo: devem tomar a iniciativa de estabelecer contato com fornecedores estrangeiros, no sentido de detectar oportunidades de parcerias; formular projetos, identificando 
as atividades que serão desenvolvidas, estabelecer a responsabilidade de cada parte envolvida, definir cronograma e os custos da operação, bem como um plano de negócios adequado ao projeto e cumprir as obrigações assumidas perante o Acordo de Offset. Porém, é necessário que as empresas que atuam nesse seguimento estejam preparadas tecnologicamente para atuar nesse mercado, que tem por principal característica um alto grau de concentração (MELLO ET AL., 2003).

\section{INDÚSTRIA DE DEFESA AÉREA NO BRASIL}

A indústria aeronáutica seja em que lugar for tem como principal característica a competitividade. A inovação tecnológica e a influência direta do setor público são fatores relevantes para a determinação do sucesso desse seguimento. As externalidades e os efeitos spin off também são marcantes, além do seu alto grau de concentração. Esse fenômeno se iniciou após a Segunda Grande Guerra e avançou até os dias atuais, culminando com a redução drástica do número de fabricantes de aeronaves ocasionada pelas grandes fusões de empresas no setor.

EUA, Reino Unido, Alemanha e França são bons exemplos da concretização desse fenômeno. Atualmente nos EUA, na aviação comercial, prevalece a supremacia da Boeing e, na Europa, a Airbus. No Canadá surgiu a Bombardier, que foi privatizada em 1986, onde se estabeleceu como potência no seguimento de jatos executivos regionais (PURSELL, 1979).

Pelo lado brasileiro, temos a Empresa Brasileira de Aeronática (Embraer) que nasceu como estatal e foi privatizada em 1994. A contratação de recursos humanos de alta qualidade, associado a uma gestão eficiente e políticas bem definidas nas áreas de logística e pesquisa, fizeram com que a empresa se tornasse parte do seleto grupo das quatro maiores fabricantes de aeronaves no mundo.

\subsection{CAPACIDADE DE PRODUCÇ̃̃O}

A capacidade da cadeia produtiva da indústria aeronáutica brasileira é um segmento que ainda demanda muito investimento. A Embraer e a Helibrás destacamse num setor que apresenta pouco mais de 50 empresas e destas apenas 20 se apresentam com capacidade de se manter de forma continuada neste seguimento. Estas empresas são de extrema importância na cadeia produtiva em função da necessidade do fornecimento de itens e/ou serviços às fabricantes de aeronaves como Embraer e Helibrás, além de fabricantes internacionais envolvidas em subcontratações ou como parte beneficiária em acordos de compensação comercial.

A Helibrás por ser uma empresa de capital fechado, pouco divulga os seus números, contudo, no mercado há pelo menos 30 anos surge como uma promessa para o setor de aeronaves de asas rotativas. A Helibrás firmou contrato com o Governo Federal para fornecimento de 50 helicópteros de médio porte EC-725, sendo: 16 para a Marinha, 16 para o Exército e 16 para a Aeronáutica, e mais 2 VIP para atender à Presidência da República. Essa aquisição também possui Acordo de Offset onde há a previsão de nacionalização progressiva, com transferência de tecnologia, dessa aeronave.

A Embraer é beneficiária direta em muitos contratos das Forças Armadas para o desenvolvimento de produtos de defesa, ou seja, tem em sua carteira de clientes o Governo Federal, por meio dos contratos firmados para atender projetos militares.

\section{CONSIDERACÕ̃ES FINAIS}

A indústria brasileira do setor aeronáutico tem se beneficiado dos Acordos de Offset. Porém, o país ainda recente de uma política de Estado voltada ao desenvolvimento de sua Base Industrial de Defesa. 0 estabelecimento de uma estrutura de governo formal que reúna representantes da indústria, do próprio 
governo, da academia e de centros de pesquisa é de fundamental importância ao desenvolvimento de uma política nacional que subsidie as ações de governo em prol de sua base industrial.

Os benefícios obtidos em razão dos Acordos de Offset firmados desde 1950 são inegáveis e comprovam a tese de que esses acordos quando executados com eficiência trazem benefícios extraordinários à indústria nacional.

\section{REFERÊNCIAS}

AZEVEDO, Simone e BARCELLOS, Marta. Histórias do mercado de capitais no Brasil. Rio de Janeiro: Elsevier, 2011.

BRASIL. Lei $\mathbf{n}^{\mathbf{8}} \mathbf{8 . 6 6 6}$, de 21 de junho de 1993. Regulamenta o art. 37, inciso XXI, da Constituição Federal, institui normas para Licitações e Contratos da Administração Pública. Brasília-DF, 1993.

BRASIL. Constituição (1988). Constituição Federal da República Federativa do Brasil. Brasília-DF: Senado 1988.

BRASIL. Portaria n 1.396/GC-4, de 13 de dezembro de 2005. Gabinete do Comando da Aeronáutica. Brasília, DF, 2005.

\section{BRASIL. Instrução do Comando da Aeronáutica 360-}

$\mathbf{1 / 2 0 0 5}$. Estabelece os preceitos para a negociação de acordos de compensação comercial, industrial e tecnológica na Aeronáutica. Brasília-DF, 2005.

BRASIL. Decreto $\mathbf{n}^{\mathbf{6}} \mathbf{6 . 7 0 3}$, de 18 de dezembro de 2008, aprova a Estratégia Nacional de Defesa (END). Brasília, DF, 2008.

BRASIL. Decreto-lei no 991, de 21 de outubro de 1969. Dá nova redação ao Decreto-lei nº 200, de 25 de fevereiro de 1967. Brasília-DF, 1969.
BRASIL. Ministério da Defesa. Política Nacional de Defesa e Estratégia Nacional de Defesa. Disponível em: <www.defesa.gov.br>. Acesso em: 23 mar. 2015.

BRAUER, Jurgen; DUNNE, Paul. Arms trade and economic development: Theory, Policy and Cases. In: Arms Trade Offsets (Routledge Studies in Defence and Peace Economics) Hardcover. London: Routledge, 2004.

DRUMOND, Cosme. Indústria de defesa do Brasil - história - desenvolvimento - desafios. São Paulo: ZLC, 2014.

DW. MAD FOR MINDS. Disponível em: <www.dw.de>. Acesso em: 26 mar. 2015.

ERIKSSON, E. Anders. et al. Study on the effects of offsets on the development of a european defense industry and market. FOI, 2007.

GOYZUETA, Verónica. Novos rumos para a defesa brasileira. Desafios do desenvolvimento, v.7, n.59, Brasília, fev-mar. 2010. p.42-47.

\section{HISTÓRIA da Embraer. Centro histórico Embraer.}

Disponível em: <http://www.centrohistoricoembraer. com.br>. Acesso em 26 fev. 2015.

CUNHA, Rudnei Dias da. História da força aérea brasileira. Disponível em: <http://www.rudnei. cunha.nom.br>. Acesso em: 22 fev. 2015.

EIGHTEENTH Study - Offsets in Defense Trade - U.S. Department of Commerce - Bereau of Industry and Secrurity, 2013. p.13. Disponível em: <http://www. bis.doc.gov/>. Acesso em: 3 mar. 2015.

JACKSON, J. H. The jurisprudence of GATT and the WTO (Parte III; Trade Policy Fundamentals, Capítulo 5; Equality and Discrimination in International Economic Law; The General Agreement on Tariffs and Trade). Cambridge:Universidade de Cambridge, 2000. 
MARQUES, M. S. B. A aceleração inflacionária no Brasil: 1973-1983. Revista Brasileira de Economia, Rio de Janeiro, 1989.

MELLO, João Manuel Cardoso de; BELLUZZO, Luiz Gonzaga; HIRATUKA, Célio; SABBATINI, Rodrigo. A internacionalização de empresas no capitalismo contemporâneo: breves notas sobre a inserção competitiva da indústria petroquímica brasileira. Campinas-SP: Faculdades de Campinas (Facamp), agosto de 2003.

MOWERY, David. The Oxford Handbook of Innovation. New York: Oxford University Press, 2005.

MORCEIRO, Paulo César. Desindustrialização na Economia Brasileira no período 20002011: abordagens e indicadores. 2012. $206 f$. Dissertação (Mestrado) - Universidade Unesp, Araraquara-São Paulo, 2012.

NACKMAN, Mark J. A critical examination of offsets in international defense procurements: policy options for the United States. Public Contract Law Journal, v.40, n.2, 2011. p.511-530.

OFFSETS in Defense Trade. Seventh Study. BIS, July 2003. Disponível em: <www.bis.doc.gov/ defenseindustrialbaseprograms>. Acesso em: 20 jan. 2015.
PURSELL,Carroll W. Science Agencies in World War II: The OSRD and Its Challengers. In: REINGOLD, Nathan (Ed.). The Sciences in the American Context: New Perspectives. Washington, D.C.: Smithsonian Institution Press, 1979.

SALZMANN, B. The Help Avaible on Offset and Countertrade in the UK. In: WARWAR, Z. (Ed.).

Panorama da pratica do offset no Brasil - uma visão da negociação internacional de acordos de compensacão comercial, industrial e tecnológica. Brasília: Suspensa, 2004. p.217-242.

\section{SCHUMPETER, Joseph. Capitalismo, Socialismo e}

Democracia. Rio de Janeiro: Zahar, 1984.

SINGER, Paul. O Milagre Brasileiro - Causas e Consequências. Caderno Cebrap, n.6, São Paulo, 1972.

UNITED States of America, Department of Commerce. 11 Offset Report on Trade Military. 2007. 256f. Report (ostensible) - Government North American, Washington-USA, 2007.

VILSON. Sensores inerciais fotônicos para aplicações aeroespaciais: nível de maturidade tecnológica, CCEM-ECEMAR, 2008. 
Recebido em: 20 de Novembro de 2015

Avaliado em: 12 de Dezembro de 2015

Aceito em: 19 de Dezembro de 2015
1. Graduado em Direito pelo Instituto de Ensino Superior de Brasília IESB, Pós-Graduado em Planejamento, Orçamento e Gestão Pública pela FGV,

Pós-Graduado em Gestão de Comércio Exterior e Negócios Internacionais e Mestrando pelo Centro Universitário de Brasília UNICEUB. 